\title{
Production of Karanja Methyl Ester from Crude Karanja Oil Using Meretrix Lyrata Synthesised Active Cao Catalyst
}

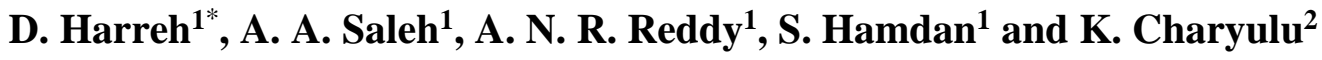 \\ ${ }^{1}$ Faculty of Mechanical Engineering, Universiti Malaysia Sarawak, \\ 94300 Kota Samarahan, Sarawak, Malaysia \\ *Email: dewiharreh@gmail.com \\ Phone: +6082583299 \\ ${ }^{2}$ Malla Reddy College of Engineering and Technology, Maisammaguda, \\ Dullapally, Hyderabad, Telangana 500043, India
}

\begin{abstract}
Active calcium oxide catalyst was synthesised from Meretrix Lyrata (M.Lyrata) following calcination-hydration-dehydration technique. The catalytic feasibility of synthesised $\mathrm{CaO}$ was investigated in the production of Karanja methyl ester (KME) from crude Karanja oil (CKO). KME was synthesised through esterification using $\mathrm{H}_{2} \mathrm{SO}_{4}$ followed by transesterification utilising $\mathrm{CaO}$ in a two-step reaction process of $\mathrm{CKO}$ and methanol. The M.Lyrata shells were calcined at $900{ }^{\circ} \mathrm{C}$ and the catalyst samples were characterised using FTIR, SEM, PSA, and BET-BJH spectrographic techniques. A maximum fatty acid methyl ester (FAME) conversion of $97.3 \%$ was obtained at optimum reaction conditions including methanol-to-oil ratio of $12: 1$, catalyst concentration of 2 wt. $\%$, reaction temperature of $58{ }^{\circ} \mathrm{C}$ and reaction time of $2 \mathrm{hrs}$. In a comparative study with commercial $\mathrm{CaO}$, M.Lyrata showed a higher catalytic activity. The catalyst reusability experiments ascertaining reusability of $\mathrm{CaO}$ up to four reuse cycles had shown good efficiency. The economic comparative study confirms that $\mathrm{CaO}$ derived from M.Lyrata can be used as an alternative and feasible catalyst for biodiesel production. The KME fuel properties complied to EN-14214 biodiesel fuel standards.
\end{abstract}

Keywords: Seashells; heterogeneous catalyst; transesterification; Karanja biodiesel; spectroscopy.

\section{INTRODUCTION}

Biodiesel, also known as fatty acid methyl ester (FAME) or fatty acid ethyl ester (FAEE) can be obtained from vegetable oils or animal fats [1,2]. The rapid depletion of fossil fuel, demand for engine fuels that keeps growing tremendously and its unpredictability in future availability, lead to the crucial factor to explore on alternative renewable fuel sources that will be able to supplement fossil fuels [3-6]. In recent years, biodiesel had shown exciting potential and received worldwide attention being recognised as a substitute for petro-based diesel fuel. Biodiesel is known for its sustainability, nontoxicity, biodegradability, reduced gaseous pollutant emissions and easy usability as fuel to be used in conventional diesel engines without major modifications as compared to petroleum diesel [7, 8]. Production of biodiesel globally was over 5 billion gallons in 2010. Transesterification is considered to be the most reliable method for biodiesel production using vegetable oil feedstocks $[9,10]$. There are several types of catalysts used for biodiesel production via transesterification reaction such as homogenous catalyst, heterogeneous catalyst and certain enzymes [11-13]. Usually $\mathrm{KOH}$ or $\mathrm{NaOH}$ are 
frequently being used as base homogenous catalyst, since the rate of reaction is relatively fast [14-16]. Unfortunately, the use of homogenous catalyst causes a high volume of wastewater discharged during the purification or washing process of biodiesel production in order to remove the residual catalyst present. This results in water contamination as well as increase the cost of water treatment plants. The used catalyst from the reaction cannot be recovered and reutilised backed into the process. Severe problems might arise such as formation of soap during transesterification which is caused by the presence of large amount of FFA content in vegetable oil. This will cause a decrease in catalytic efficiency [17-19]. Contrary to homogenous catalyst, heterogeneous catalyst has a number of benefits; for instance, utilisation of heterogeneous catalyst which is easily separable from biodiesel product and recyclable. This leads to an economical way for biodiesel production by reducing the consumption of wastewaters and can be reused for next transesterification [20].

In recent times, research studies on the use of calcium oxide $(\mathrm{CaO})$ as a heterogeneous catalyst have been carried out owing to its low cost $[21,22]$ and high basicity [23]. Additionally, $\mathrm{CaO}$ is readily availability in nature, and can be derived from natural waste materials such as seashell, rice husk, egg shell, mussel shell and chicken bones making the production of biodiesel more cost-effective, added further by its low stability, non-toxicity and high basic properties [24-26]. This present research focuses on synthesis of active $\mathrm{CaO}$ catalyst using locally available waste seashells as raw material. An economically feasible laboratory scale synthesis technique, calcination-hydrationdehydration is adopted in the $\mathrm{CaO}$ synthesis. Newly synthesised catalyst samples were characterised using FTIR, SEM, PSA, and BET-BJH spectrographic techniques. Karanja methyl ester (KME) production was experimented with newly synthesised active $\mathrm{CaO}$ using a two-step transesterification protocol.

\section{EXPERIMENTAL SET UP}

\section{Materials}

The crude Karanja oil (CKO) was extracted from their seeds using soxhlet apparatus and mechanical expeller. According to Mahanta and Shrivastava (2004), soxhlet apparatus yielded better quality and higher amount of vegetable oil [27]. Experimental data revealed acid value and saponification value for CKO as $5.06 \mathrm{mg} \mathrm{KOH} / \mathrm{mg}$ and $187 \mathrm{mg} \mathrm{KOH} / \mathrm{mg}$, respectively [28]. The laboratory grade chemicals that include methanol $(\mathrm{MeOH} ;>99 \%$ pure), $\mathrm{H}_{2} \mathrm{SO}_{4}(95-97 \%)$, calcium oxide, distilled water and $\mathrm{NaOH}$ were used for experimental protocols. The biodiesel production was carried out at the Energy Laboratory of the Faculty of Engineering, Universiti Malaysia Sarawak (UNIMAS) Sarawak, Malaysia.

\section{Catalyst Synthesis}

Initially, the M.Lyrata shells were collected from a local market situated at Samarahan, Sarawak, Malaysia. The shells were then rinsed simultaneously using tap, hot and distilled water to remove any dirt and stain as well as impurities on the shells surface [29]. M.Lyrata shells were dried overnight in a hot-air oven at $105^{\circ} \mathrm{C}$ [30]. The dried shells were then grinded to fine powder form using a commercial blender and sieved through an $80 \mu \mathrm{m}$ mesh. The $\mathrm{CaO}$ derived from M.Lyrata was calcined at $900{ }^{\circ} \mathrm{C}$ for $2 \mathrm{hrs}$ in a muffle furnace (KSL-1700X-A4, MTI Corporation, USA), then the shell powders were 
refluxed in distilled water for $6 \mathrm{hrs}$ at $60{ }^{\circ} \mathrm{C}$. The samples were filtered and dried overnight at $120^{\circ} \mathrm{C}$ for $3 \mathrm{hrs}$ as well as recalcined for $3 \mathrm{hrs}$ at $600^{\circ} \mathrm{C}$ to produce fine calcium oxide. The $\mathrm{CaO}$ samples were dried in a hot air oven at $100{ }^{\circ} \mathrm{C}$ for $1 \mathrm{hr}$ and finally stored in an air-tight sample bottle [29]. Thus, the $\mathrm{CaO}$ was successfully synthesised as an active heterogeneous $\mathrm{CaO}$ catalyst synthesis from M.Lyrata by 'calcination-hydrationdehydration' technique.

\section{CaO Catalyst Characterisation}

The chemical composition of M.Lyrata shells synthesised $\mathrm{CaO}$ was evaluated over the wavelength region of $600 \mathrm{~cm}^{-1}$ to $4000 \mathrm{~cm}^{-1}$ by employing Fourier Transform Infrared Spectrophotometer (FTIR) (Perkin Elmer Model 100 series). A scanning electron microscope (SEM) (Hitachi TM3030) was utilised to study the particle morphologies and elemental analysis of both calcined $\mathrm{CaO}$ and commercial $\mathrm{CaO}$. A particle size analyser (PSA) (CILAS-1090) was used to analyse particle size distribution of M.Lyrata shells synthesised catalyst. The surface area of calcined M.Lyrata seashell and commercial $\mathrm{CaO}$ were estimated using Brunauer-Emmett-Teller (BET) equation while pore diameter was determined using Barrett-Joyner-Halenda (BJH) [31, 32].

\section{M.Lyrata CaO Catalyst Economic Synthesis Study}

M.Lyrata are available abundantly in the state of Sarawak, Malaysia and largely consumed as a food source. Thus utilisation of M.Lyrata waste shells as a renewable source is substantially potential. Further, shell-based wastes were utilised as renewable sources for synthesising heterogeneous catalysts for producing biodiesels.

\section{Experimental Set Up for Biodiesel Production}

The free fatty acid (FFA) contents of CKO range over 20\% which results in lowering biodiesel yield especially in transesterification of vegetable oils using heterogeneous solid catalyst $[29,33]$. Since the FFA of CKO is higher than the required value $(>1 \%)$, KME derived from CKO is achieved by a two-step process [33]. According to Ahmad et.al, transesterification process transforms crude oil to fatty acid methyl ester [34]. The KME was produced by performing pre-treatment (esterification) followed by alkaline (base catalysed) transesterification [9].

Esterification: Initially, CKO was heated up to $100{ }^{\circ} \mathrm{C}$ for $30 \mathrm{~min}$. to remove moisture, then acid pre-treatment process was applied to reduce the FFA content by using $0.8 \% \mathrm{H}_{2} \mathrm{SO}_{4}$ (v/v) added to oil, and next mixed with 6:1 (methanol-to-oil ratio) molar ratio. The solution was heated to $50{ }^{\circ} \mathrm{C}$ and stirred for $90 \mathrm{~min}$. Subsequently, the solution was transferred to a separating funnel which was then allowed to settle for $2 \mathrm{hrs}$. The methyl ester was washed three times using distilled water and the layers of oil from methanol and $\mathrm{H}_{2} \mathrm{SO}_{4}$ were separated. The pre-treated oil was heated up to $100{ }^{\circ} \mathrm{C}$ to remove excess water content [34-39].

Transesterification: This is the second step of biodiesel production process. The pretreated $\mathrm{CKO}$ was mixed with methanol at a molar ratio of $12: 1$ and $\mathrm{CaO}$ catalyst concentration of $2 \mathrm{wt} . \%$ at $60{ }^{\circ} \mathrm{C}$. The reaction then proceeded with stirring at $250 \mathrm{rpm}$ for $2 \mathrm{hrs}$ using a magnetic stirrer. The reaction mixture was transferred to a separating funnel for separation of 2 layers where the upper layer consists of KME while the lower layer consists of glycerol [40]. 


\section{Catalyst Reusability Study}

Karanja biodiesel and other mixtures were centrifuged at $3000 \mathrm{rpm}$ for $1 \mathrm{hr}$ to recover M.Lyrata shells $\mathrm{CaO}$ catalyst and then washed using n-hexane for three times to remove all dissolved impurities. The sample was then dried in an oven for $24 \mathrm{hrs}$. Then, the recovered catalyst recalcined again before being used for the next transesterification of $\mathrm{CKO}$ for $3 \mathrm{hrs}$ at $600{ }^{\circ} \mathrm{C}$.

\section{RESULTS AND DISCUSSION}

\section{Catalyst Characterisation Analysis}

The infrared (IR) spectrum of $\mathrm{CaO}$ catalyst as synthesised from M. Lyrata shells is graphically shown in Figure 1. It is evident that $\mathrm{CaO}$ group absorptions were strongly attributed less than $700 \mathrm{~cm}^{-1}$ corresponding to the functional group Ca-O from calcium carbonate. The peak indicates strong as well as broad medium absorptions band signifying the $\mathrm{Ca}-\mathrm{O}$ which confirms the presence of $\mathrm{CaO}$. The absorption peak over $854.47 \mathrm{~cm}^{-1}$ corresponds to $\mathrm{C}-\mathrm{Cl}$ stretching, while the absorption band over wavelength $1469.76 \mathrm{~cm}^{-1}$ and $1454.33 \mathrm{~cm}^{-1}$ corresponds to medium $\mathrm{C}-\mathrm{H}$ bending bond. Furthermore, a weak absorption wavelength of more than $3700 \mathrm{~cm}^{-1}$ specifically can be seen at $3639.68 \mathrm{~cm}^{-1}$ where the absorption peaks correspond to the hydroxyl group due to the presence of calcium hydroxide.

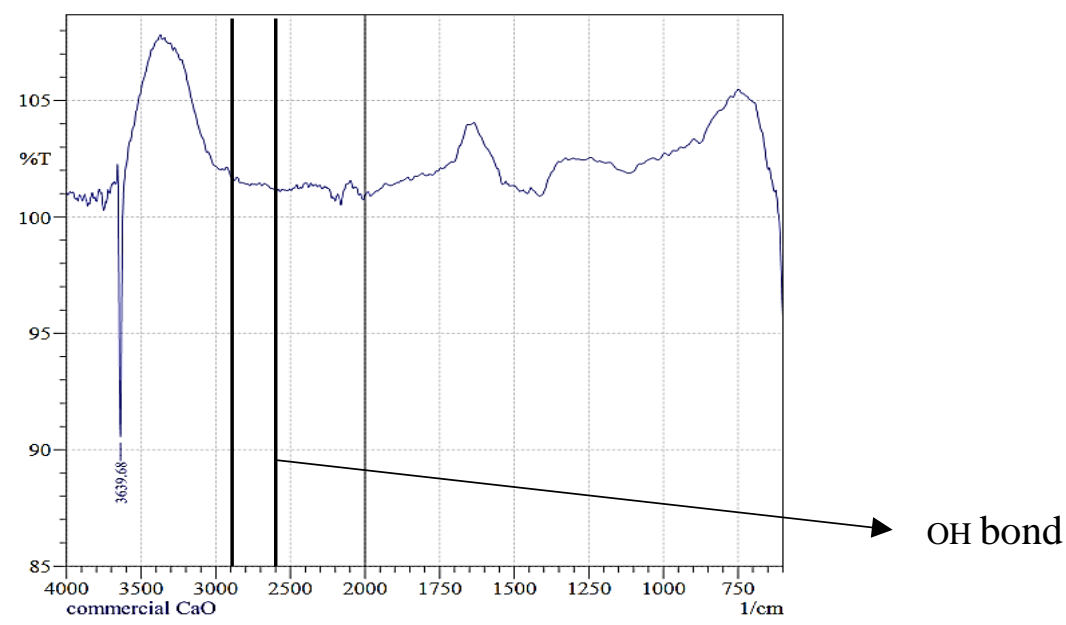

(a) 


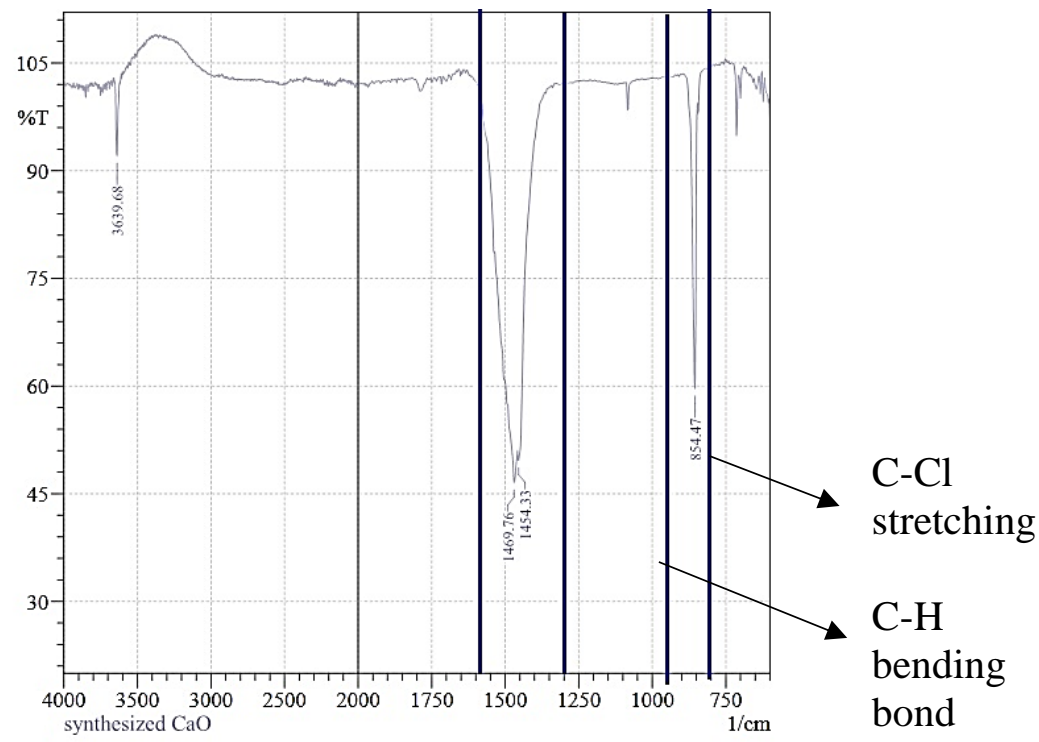

(b)

Figure 1. FTIR spectrum of (a) commercial $\mathrm{CaO}$ and; (b) synthesised $\mathrm{CaO}$ from $M$. Lyrata.

The surface morphology of calcium oxide derived from both hard-calm shell and commercial $\mathrm{CaO}$ was analysed using scanning electron microscopy (SEM). Referring to Figure 2(a), it can be observed clearly that SEM images of $\mathrm{CaO}$ derived from hard calm shell is totally different from commercial $\mathrm{CaO}$. SEM images of calcium oxide synthesised from hard calm shell show a porous structure with smaller particles. According to Buasri et al., smaller sizes of grains and aggregates of M. Lyrata $\mathrm{CaO}$ could give a higher specific surface area $[18,19]$. Conversely, the commercial $\mathrm{CaO}$ particles appear in agglomerate forms as shown in Figure 2(b).

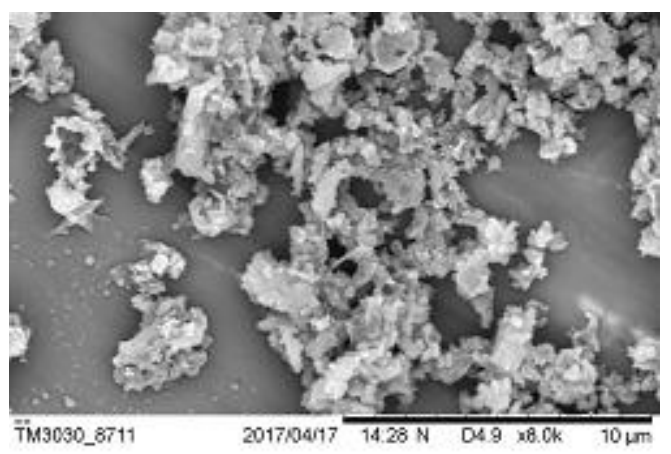

(a)

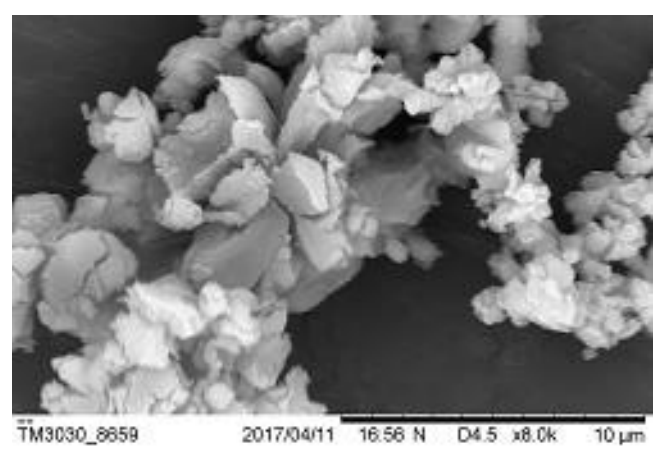

(b)

Figure 2. SEM images of (a) synthesised $\mathrm{CaO}$ and; (b) commercial catalyst.

Figure 3 shows the particle size distribution of $\mathrm{CaO}$ particles from hard clam shells where the particle distribution is in the range of 0.04 to $60 \mu \mathrm{m}$. A large fraction of the powder particle falls within a range of $20-40 \mu \mathrm{m}$. The average particle diameter was 15.67 $\mu \mathrm{m}$. The highest peak of the bimodal size distribution ranges from 30-60 $\mu \mathrm{m}$. The BET and $\mathrm{BJH}$ analysis of $M$. Lyrata synthesised having a $\mathrm{S}_{\mathrm{BET}}$ of $36.6 \mathrm{~m}^{2} / \mathrm{g}$ yield pore diameters of $13.861 \mathrm{~nm}$ and total pore volume of $0.126 \mathrm{cc} / \mathrm{g}$. Further, commercial $\mathrm{CaO}$ 
having a $\mathrm{S}_{\mathrm{BET}}$ of $5.21 \mathrm{~m}^{2} / \mathrm{g}$ results in pore diameters of $11.355 \mathrm{~nm}$ and total pore volume of $0.0121 \mathrm{cc} / \mathrm{g}$. According to Ren et al., the results $\mathrm{S}_{\mathrm{BET}}$ of M.Lyrata is comparatively high and the pore diameter ranges are categorised within mesopores $2 \mathrm{~nm}$ to $50 \mathrm{~nm}$ consequently, resulting in high surface area along with their catalytic activity, able to store energy and suitable of adsorption [32, 41].

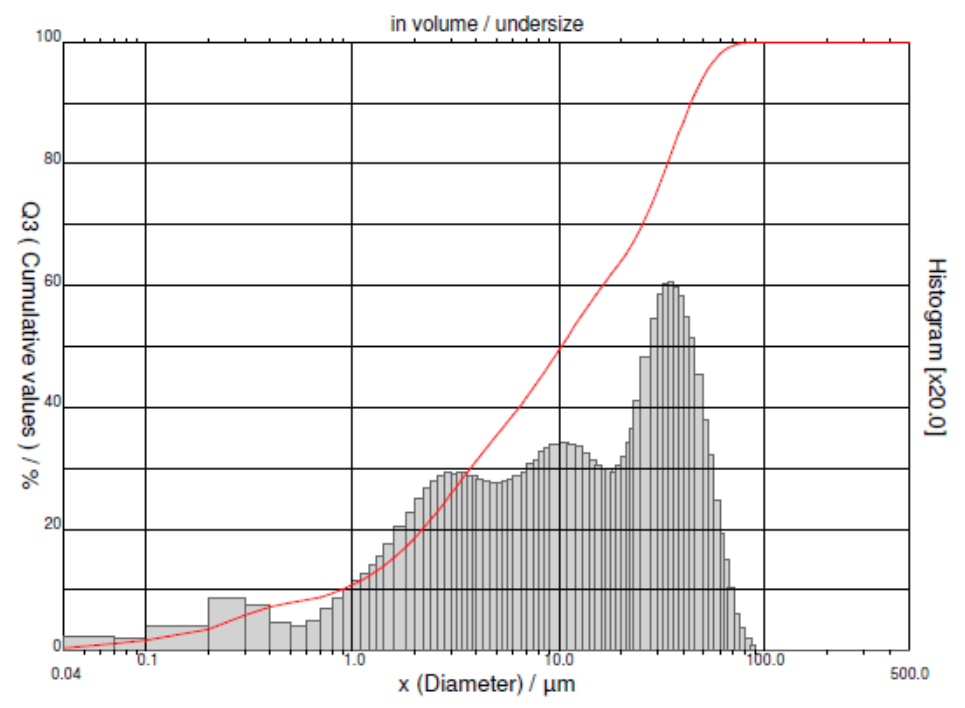

Figure 3. Particle size distribution of $\mathrm{CaO}$ synthesised from M. Lyrata.

\section{Economic Analysis of CaO Synthesised from M. Lyrata}

From economical point of view, attentions have been focused on making $\mathrm{CaO}$ as a candidate for solid base catalyst. As a major source, $\mathrm{CaO}$ has its own ready availability and of low cost. Moreover, $\mathrm{CaO}$ can be prepared at laboratory scale thus resulting in economic benefit.

\section{Karanja Biodiesel Production Analysis}

In heterogenous transesterification, CKO was mixed with methanol and catalysed by alkaline earth oxide, $\mathrm{CaO}$. The influence of reaction time, reaction temperature, catalyst concentration and methanol ratio on the performance of synthesised $\mathrm{CaO}$ under different transesterification conditions were investigated. Based on the results tabulated in Table 1 , higher methyl ester yield for transesterification of using synthesised $\mathrm{CaO}$ catalyst is achieved at $97.3 \%$ in the presence of 2 (wt. \%) $\mathrm{CaO}$ using methanol-to-oil ratio of 12:1 at $58{ }^{\circ} \mathrm{C}$ temperature within $2 \mathrm{hrs}$. Figure 4(a) to 4(d) present the optimal reaction parameters for KME production via a two-step transesterification.

The optimum methanol-to-oil ratio was 12:1 over the catalyst in the present study, which was double the practical methanol-to-oil ratio for homogeneous transesterification of 6:1. This higher amount methanol would cause the development of methoxy specified for the surface of $\mathrm{CaO}$ as well as the reaction equilibrium shifting to a forward direction [42]. However, KME yield will not increase when the methanol ratio is over 12. The reason for this is glycerol eventually dissolved in excessive methanol and at the same time constrained the reaction of methanol to the reactants and catalyst. However, further increase in methanol/oil ratio up to $18 \mathrm{did}$ not promote the reaction. It was considered that the glycerol would largely dissolve in excessive methanol and subsequently inhibited the 
reaction of methanol to the reactants and catalyst [41, 43]. From the results, by comparing with commercial $\mathrm{CaO}$, hard clam showed a higher catalytic activity. Optimum conditions of this catalyst were achieved by giving a FAME conversion of $97.3 \%$ when the methanol-to-oil ratio of $12: 1$ in the presence of 2 (wt.\%) catalyst at $58{ }^{\circ} \mathrm{C}$ for $2 \mathrm{hrs}$ of reaction time.

Table 1. Effect on various parameters on production of Karanja methyl ester (KME)

\begin{tabular}{cccccccc}
\hline \multicolumn{2}{c}{$\begin{array}{c}\text { Catalyst loading, } \\
\text { CL }\end{array}$} & \multicolumn{2}{c}{ Methanol ratio, MR } & \multicolumn{2}{c}{ Transesterification time, } \\
TT & \multicolumn{2}{c}{$\begin{array}{c}\text { Reaction temp., } \\
\text { RT }\end{array}$} \\
\hline CD & KMEY & MR & KMEY & TT & KMEY $(\%)$ & RT & KMEY \\
$($ wt.\% $)$ & $(\%)$ & $($ mol. $)$ & $(\%)$ & $($ min $)$ & & $\left({ }^{\circ}\right.$ C) & $(\%)$ \\
\hline 1 & 78 & 8 & 69 & 60 & 81 & 50 & 86 \\
2 & 94 & 10 & 83 & 90 & 90 & 55 & 92 \\
3 & 97 & 12 & 97 & 120 & 95 & 60 & 96 \\
4 & 90 & 14 & 92 & 180 & 87 & 65 & 90 \\
\hline
\end{tabular}

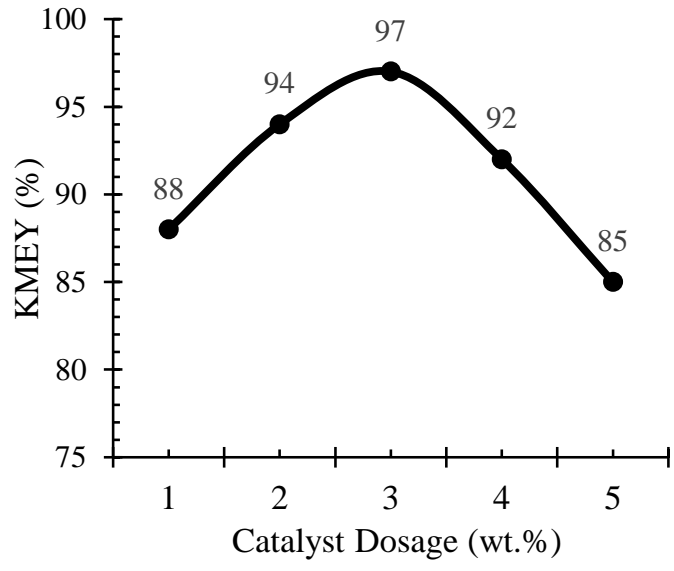

(a)

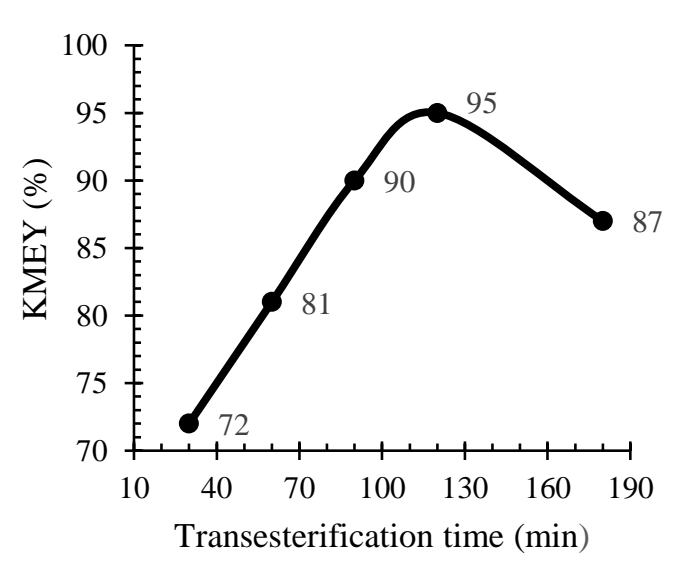

(c)

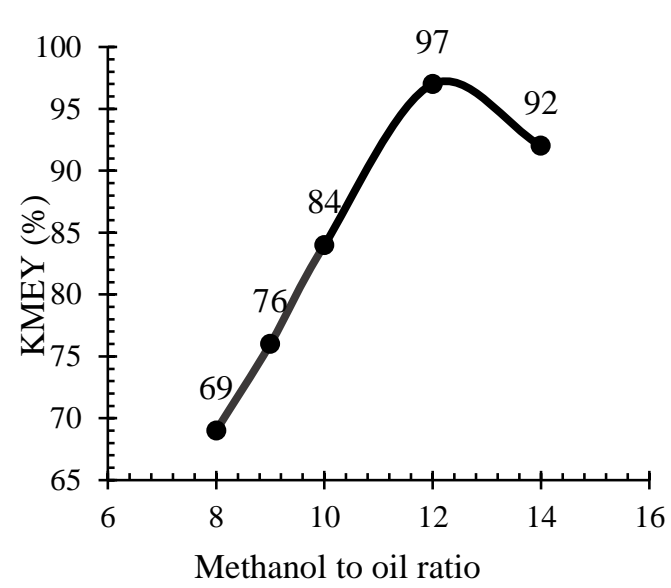

(b)

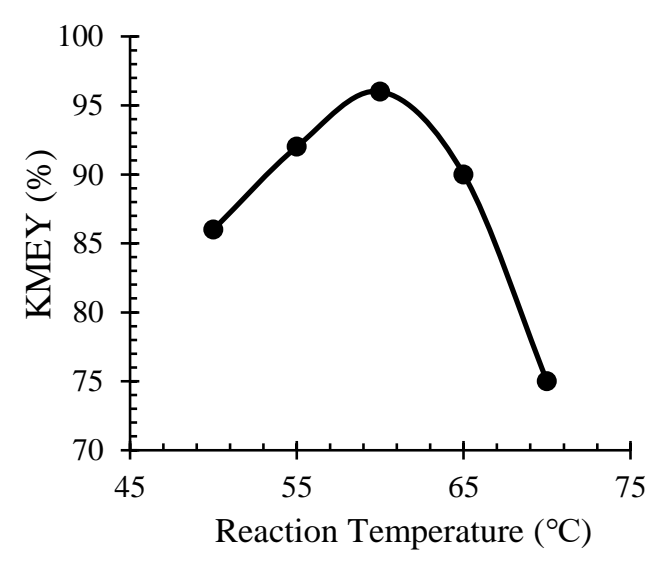

(d)

Figure 4. Optimisation of KME yield via two-step transesterification responding to (a) catalyst dosage, (b) methanol to oil ratio, (c) transesterification time and; (d) reaction temperature. 


\section{Lyrata Synthesised CaO Reusability Analysis}

The M.Lyrata catalyst reusability was studied by using optimal condition of transesterification at a molar ratio of $12: 1$ and catalyst concentration of $2 \mathrm{wt} . \%$ at $58{ }^{\circ} \mathrm{C}$ for $2 \mathrm{hrs}$. After the reaction was completed, separation of catalyst from the mixture was made and proceeded to be used for a second reaction under the same conditions. From Figure 5, it is observed that the catalyst is active for three reaction cycles with yield above $90 \%$. It is also found out that after four reaction cycles, the biodiesel yield lowers to 83.7 $\%$. The reason for this is catalyst deterioration occurring due to the change in surface structure causing loss of active sites in the synthesised catalyst. Moisture in the reactant caused the calcium oxide to transform into calcium hydroxide which deteriorated the catalyst activity. However, by recalcining the catalyst at $600{ }^{\circ} \mathrm{C}$ the catalyst activity could recover [8,44]. Table 2 and Table 3 show the analysis and the test methods adopted for the determination of $\mathrm{CKO}$ methyl esters properties.

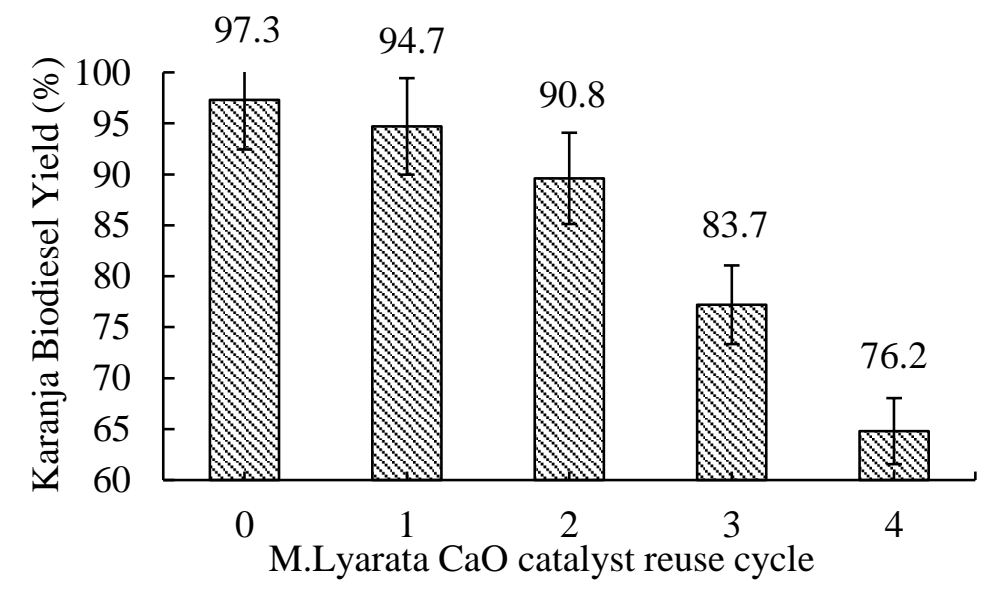

Figure 5. M.Lyarata $\mathrm{CaO}$ catalyst recycle and reusability experimentation.

Table 2. Properties of KME and test methods.

\begin{tabular}{lccc}
\hline Property & KME & Limits & EN 14214/ASTM \\
\hline Density at $15^{\circ} \mathrm{C}\left(\mathrm{g} \mathrm{cm}^{-3}\right)$ & 0.883 & $0.860-0.900$ & EN ISO 3675 \\
Pour point $\left({ }^{\circ} \mathrm{C}\right)$ & 3 & $\mathrm{NS}^{\mathrm{a}}$ & ASTM D 97 \\
Water content $(\%)$ & 0.038 & $0.05 \mathrm{max}$ & EN ISO 12937 \\
Acid value, Koh, $\left(\mathrm{mg} \mathrm{g}^{-1}\right)$ & 0.17 & $0.5 \mathrm{max}$ & EN 14104 \\
Kinematic viscosity at $40{ }^{\circ} \mathrm{C}$ & $4.66 \pm$ & $3.50-5.00$ & EN ISO 3104 \\
$\left(\mathrm{mm}^{2} / \mathrm{s}\right)$ & 0.02 & & \\
Flash point $\left({ }^{\circ} \mathrm{C}\right)$ & 212 & $120 \mathrm{~min}$ & EN22719 \\
Cloud point $\left({ }^{\circ} \mathrm{C}\right)$ & 6 & $\mathrm{NS}^{\mathrm{a}}$ & EN14214 \\
Free glycerin $(\mathrm{wt} . \%)$ & 0.0064 & 0.02 & ASTM D6584 \\
Total glycerin $(\mathrm{wt} . \%)$ & 0.082 & 0.240 & ASTM D6584 \\
Monoglyceride content $(\mathrm{wt} . \%)$ & 2.63 & $<0.8$ & EN4214 \\
Phosphorus $(\mathrm{mg} / \mathrm{kg})$ & 0.04 & $<4-10$ & ASTM D4951 \\
Triglyceride content $(\mathrm{wt} . \%)$ & 0.06 & $<0.2$ & EN4214 \\
Diglyceride content $(\mathrm{wt} . \%)$ & 0.78 & $<0.2$ & EN4214 \\
Group 1 metals, $\mathrm{Na}+\mathrm{K}(\mathrm{mg} / \mathrm{kg})$ & - & 0.5 & EN14214 \\
\hline
\end{tabular}


Table 2. Properties of CKO before transesterification and test methods.

\begin{tabular}{llc}
\hline Properties & CKO & EN 14214/ASTM \\
\hline Density at $15^{\circ} \mathrm{C}(\mathrm{g} / \mathrm{ml})$ & 0.924 & EN ISO 3675 \\
Water content $(\%)$ & 10.20 & EN ISO 12937 \\
Saponification number $(\mathrm{mg} / \mathrm{g})$ & 186.4 & ASTM D5558 \\
Acid number $(\mathrm{mg} \mathrm{KOH} / \mathrm{g}$ oil $)$ & 31.24 & EN 14104 \\
FFA $(\%)$ & 15.62 & ASTM D5555 \\
Kinematic viscosity at $40^{\circ} \mathrm{C}\left(\mathrm{mm}^{2} / \mathrm{s}\right)$ & 27.82 & EN ISO 3104 \\
\hline
\end{tabular}

\section{CONCLUSION}

In this study, $\mathrm{CaO}$ catalyst was successfully synthesised from M.Lyrata seashells by following a calcination - hydration - dehydration technique. The characterisation of newly synthesised $\mathrm{CaO}$ was carried out using FTIR, SEM, PSA, BET and BJH. BET and $\mathrm{BJH}$ are spectro-photographic techniques. The characterisation results revealed that the synthesised $\mathrm{CaO}$ catalyst had $\mathrm{S}_{\mathrm{BET}}$ of $36.6 \mathrm{~m}^{2} / \mathrm{g}$, pore diameters of $13.861 \mathrm{~nm}$ and total pore volume of $0.126 \mathrm{cc} / \mathrm{g}$. Under optimum transesterification reaction conditions of methanol-to-oil ratio of $12: 1$ in the presence of $2 \mathrm{wt} . \%$ catalyst at $58{ }^{\circ} \mathrm{C}$ for $2 \mathrm{hrs}$ of reaction time, a KME yield of $97.3 \%$ was obtained. It was observed that the catalyst was active for 3 reaction cycles with yield above $90 \%$. The produced KME fuel properties were tested according to EN 14214 biodiesel standards.

\section{ACKNOWLEDGEMENT}

The authors would like to acknowledge Universiti Malaysia Sarawak (UNIMAS) for providing technical and financial assistance during this work under the grant F02/SpFRGS/1538/2017.

\section{REFERENCES}

[1] Lee SB, Lee JD, Hong IK. Ultrasonic energy effect on vegetable oil based biodiesel synthetic process. Journal of Industrial and Engineering Chemistry. 2011;17:138-43.

[2] Baskar G, Aberna Ebenezer Selvakumari I, Aiswarya R. Biodiesel production from castor oil using heterogeneous $\mathrm{Ni}$ doped $\mathrm{ZnO}$ nanocatalyst. Bioresource Technology. 2018;250:793-8.

[3] Mobilia M, Comstock O. U.S. energy consumption rose slightly in 2016 despite a significant decline in coal use. Today in Energy: U.S. Energy Information Administration (EIA); 2017.

[4] Bai H-x, Shen X-z, Liu X-h, Liu S-y. Synthesis of porous CaO microsphere and its application in catalyzing transesterification reaction for biodiesel. Transactions of Nonferrous Metals Society of China. 2009;19:s674-s7.

[5] Krawczyk T. Biodiesel-Alternative Fuel Makes Inroads But Hurdles Remain. Inform. 1996;7:801-15.

[6] Caliskan H. Environmental and enviroeconomic researches on diesel engines with diesel and biodiesel fuels. Journal of Cleaner Production. 2017;154:125-9. 
[7] Watcharathamrongkul K, Jongsomjit B, Phisalaphong M. Calcium oxide based catalysts for ethanolysis of soybean oil. Songklanakarin Journal of Science and Technology. 2010;32:627-34.

[8] Mazaheri H, Chyuan OH, H. MH, Zeynab A, D. HM, Chin-TsanWang, et al. Rice bran oil based biodiesel production using calcium oxide catalyst derived from Chicoreus brunneus shell. Energy. 2018;144:10-9.

[9] Ma F, Hanna MA. Biodiesel production: a review. Bioresource Technology. 1999;70:1-15.

[10] Reddy ANR, Saleh AA, Islam MS, Hamdan S. Optimization of transesterification parameters for optimal biodiesel yield from crude jatropha oil using a newly synthesized seashell catalyst. Journal of Engineering Science and Technology. 2017;12:2723-32.

[11] Agarwal AK, Katiyar V, Singh K. Optimisation of Karanja/Jatropha-Methanol emulsification variables and their engine evaluation. Renewable Energy. 2016;96:433-41.

[12] Torres-Rodríguez DA, Romero-Ibarra IC, Ibarra IA, Pfeiffer H. Biodiesel production from soybean and Jatropha oils using cesium impregnated sodium zirconate as a heterogeneous base catalyst. Renewable Energy. 2016;93:323-31.

[13] Duarte JG, Leone-Ignacio K, da Silva JAC, Fernandez-Lafuente R, Freire DMG. Rapid determination of the synthetic activity of lipases/esterases via transesterification and esterification zymography. Fuel. 2016;177:123-9.

[14] Ljupkovic R, Micic R, Tomic M, Radulovic N, Bojic A, Zarubica A. Significance of the structural properties of $\mathrm{CaO}$ catalyst in the production of biodiesel: An effect on the reduction of greenhouse gases emission. Hemijska industrija. 2014;68:399-412.

[15] Arun N, Sharma RV, Dalai AK. Green diesel synthesis by hydrodeoxygenation of bio-based feedstocks: Strategies for catalyst design and development. Renewable and Sustainable Energy Reviews. 2015;48:240-55.

[16] Abdullah, Rahmawati Sianipar RN, Ariyani D, Nata IF. Conversion of palm oil sludge to biodiesel using alum and $\mathrm{KOH}$ as catalysts. Sustainable Environment Research. 2017;27:291-5.

[17] Kesić Ž, Lukić I, Zdujić M, Mojović L, Skala D. Calcium oxide based catalysts for biodiesel production: A review. Chemical Industry and Chemical Engineering Quarterly. 2016;22:10.

[18] Rutto H, Enweremadu CC. Optimization of production variables of biodiesel using calcium oxide as a heterogeneous catalyst: an optimized process. In: Mendez-Vilas A, editor. Energy Book Series \#1: Materials and processes for energy: communicating current research and technological developments. Spain: Formatex Research Center; 2013.

[19] Islam A, Taufiq-Yap YH, Chan E-S, Moniruzzaman M, Islam S, Nabi MN. Advances in solid-catalytic and non-catalytic technologies for biodiesel production. Energy Conversion and Management. 2014;88:1200-18.

[20] Maneerung T, Kawi S, Dai Y, Wang CH. Sustainable biodiesel production via transesterification of waste cooking oil by using $\mathrm{CaO}$ catalysts prepared from chicken manure. Energy Conversion and Management. 2016;123:487-97.

[21] Buasri A, Chaiyut N, Loryuenyong V, Worawanitchaphong P, Trongyong S. Calcium Oxide Derived from Waste Shells of Mussel, Cockle, and Scallop as the Heterogeneous Catalyst for Biodiesel Production. The Scientific World Journal. 2013;2013:1-7. 
[22] Kouzu M, Hidaka J-s. Transesterification of vegetable oil into biodiesel catalyzed by $\mathrm{CaO}$ : A review. Fuel. 2012;93:1-12.

[23] Demirbas A. Biodiesel from sunflower oil in supercritical methanol with calcium oxide. Energy Conversion and Management. 2007;48:937-41.

[24] Marinković DM, Stanković MV, Veličković AV, Avramović JM, Miladinović MR, Stamenković OO, et al. Calcium oxide as a promising heterogeneous catalyst for biodiesel production: Current state and perspectives. Renewable and Sustainable Energy Reviews. 2016;56:1387-408.

[25] Li H, Niu S, Lu C, Li J. Calcium oxide functionalized with strontium as heterogeneous transesterification catalyst for biodiesel production. Fuel. 2016;176:63-71.

[26] Yan S, Kim M, Salley SO, Ng KYS. Oil transesterification over calcium oxides modified with lanthanum. Applied Catalysis A: General. 2009;360:163-70.

[27] Mahanta P, Shrivastava A. Technology development of bio-diesel as an energy alternative. Department of Mechanical Engineering Indian Institute of Technology. 2004.

[28] Thakre AR. KARANJ OIL - As a Substitute for Diesel. International Journal of Mechanical Engineering. 2011;4:135-40.

[29] Reddy ANR, Saleh AA, Islam MS, Hamdan S. Active Heterogeneous CaO Catalyst Synthesis from Anadara granosa (Kerang) Seashells for Jatropha Biodiesel Production. MATEC Web of Conferences. 2017;87:02008.

[30] Yoosuk B, Udomsap P, Puttasawat B, Krasae P. Improving transesterification acitvity of $\mathrm{CaO}$ with hydration technique. Bioresour Technol. 2010;101:3784-6.

[31] Reddy ANR, Saleh AA, Islam MS, Hamdan S, Rahman MR, Masjuki HH. Experimental evaluation of fatty acid composition influence on Jatropha biodiesel physicochemical properties. Journal of Renewable and Sustainable Energy. 2018;10:013103.

[32] Reddy ANR, Saleh AA, Islam MS, Hamdan S. Active Razor Shell CaO Catalyst Synthesis for Jatropha Methyl Ester Production via Optimized Two-Step Transesterification. Journal of Chemistry. 2017;2017.

[33] Naik M, Meher LC, Naik SN, Das LM. Production of biodiesel from high free fatty acid Karanja (Pongamia pinnata) oil. Biomass and Bioenergy. 2008;32:3547.

[34] Reddy ANR, Saleh AA, Islam MS, Hamdan S, Maleque MA. Biodiesel Production from Crude Jatropha Oil using a Highly Active Heterogeneous Nanocatalyst by Optimizing Transesterification Reaction Parameters. Energy and Fuels. 2016;30:334--43.

[35] Bobade SN, Khyade VB. Preparation of Methyl Ester (Biodiesel) from Karanja (Pongamia Pinnata) Oil. Research Journal of Chemical Sciences. 2012;2:43-50.

[36] Mane MA. Karanja Oil as an Alternative Fuel for Direct Injection CI Engine- A Review. International Journal of Science and Research. 2013;2:203-6.

[37] Meher LC, Kulkarni MG, Dalai AK, Naik SN. Transesterification of karanja (Pongamia pinnata) oil by solid basic catalysts. European Journal of Lipid Science and Technology. 2006;108:389-97.

[38] Imran HM, Khan AH, Islam MS, Niher RS, Sujan A, Chowdhury AMS. Utilization of Karanja (Pongamia pinnata) as a Major Raw Material for the Production of Biodiesel. Dhaka University Journal of Science. 2012;60:203-7.

[39] Verma P, Sharma MP. Comparative analysis of effect of methanol and ethanol on Karanja biodiesel production and its optimisation. Fuel. 2016;180:164-74. 
[40] Ismail S, Ahmed AS, Reddy ANR, Hamdan S. Biodiesel Production from Castor Oil by Using Calcium Oxide Derived from Mud Clam Shell. Journal of Renewable Energy. 2016;2016:1--8.

[41] Ren Y, Ma Z, Bruce PG. Ordered mesoporous metal oxides: synthesis and applications. Chemical Society Reviews. 2012;41:4909-27.

[42] Korkut I, Mahmut B. Selection of catalyst and reaction conditions for ultrasound assisted biodiesel production from canola oil. Renewable Energy. 2018;116:543-51 .

[43] Harreh D, Saleh AA, Reddy ANR, Hamdan S. An Experimental Investigation of Karanja Biodiesel Production in Sarawak , Malaysia. Journal of Engineering. 2018:9.

[44] Nurhayati, Muhdarina, Linggawati A, Anita S, Amri TA. Preparation and Characterization of Calcium Oxide Heterogeneous Catalyst Derived from Anadara Granosa Shell for Biodiesel Synthesis. KnE Engineering. 2016;1:1-8. 